\title{
Measuring the Openness of Innovation
}

\author{
Nicola Bellantuono ${ }^{1, *(1)}$, Pierpaolo Pontrandolfo ${ }^{2}$ (D) and Barbara Scozzi ${ }^{2}$ (1) \\ 1 Department of Agriculture, Food, Natural Resources and Engineering, University of Foggia, \\ 71121 Foggia, FG, Italy \\ 2 Department of Mechanics, Mathematics and Management Politecnico di Bari, 70126 Bari, BA, Italy; \\ pierpaolo.pontrandolfo@poliba.it (P.P.); barbara.scozzi@poliba.it (B.S.) \\ * Correspondence: nicola.bellantuono@unifg.it
}

\section{check for}

updates

Citation: Bellantuono, N.; Pontrandolfo, P.; Scozzi, B. Measuring the Openness of Innovation. Sustainability 2021, 13, 2205. https:// doi.org/10.3390/su13042205

Academic Editor: JinHyo Joseph Yun

Received: 23 December 2020

Accepted: 11 February 2021

Published: 18 February 2021

Publisher's Note: MDPI stays neutral with regard to jurisdictional claims in published maps and institutional affiliations.

Copyright: (c) 2021 by the authors. Licensee MDPI, Basel, Switzerland. This article is an open access article distributed under the terms and conditions of the Creative Commons Attribution (CC BY) license (https:// creativecommons.org/licenses/by/ $4.0 /)$.

\begin{abstract}
Measuring the openness of innovation is essential to understanding whether and under which conditions increasing openness is beneficial for organizations. However, no consensus has been so far achieved on which dimensions characterize the openness of innovation, which approach should be used to measure it, or which unit of analysis should be adopted. This paper proposes an approach, named ATOM (Aggregative Technique for Openness Measurement), to characterize and measure the openness of innovation, rooted in the concepts of knowledge supply (KS) and innovation practice (IP). As prescribed by the confirmation phase of theory building model, the approach has been successfully applied to a real innovation project. The paper contributes to clarifying the concept of innovation openness and attempts to improve its measurement by adopting a micro-level unit of analysis (i.e., single KS within an innovation project) as well as dimensions that extant literature considers relevant to managing external collaborations. The proposed approach can also support firms involved in an innovation project to (i) identify and measure the criticality of knowledge supplies, (ii) assess the openness of the adopted innovation practices, and (iii) support ex-post learning on the way the project was managed.
\end{abstract}

Keywords: open innovation; openness degree; measurement; knowledge supply; innovation practice; knowledge kind; supply type; micro-level unit of analysis; knowledge criticality

\section{Introduction}

The analysis and measurement of the innovation process are crucial to properly managing it: they are necessary to identify factors that drive, or hinder, innovation and, in general, to assess the process performance [1-3]. Outlining effective approaches to analyzing and measuring innovation is a relevant theme also with respect to open innovation [4]. To understand whether and under which conditions increasing openness is beneficial and appropriate for the development of a specific innovation is a research priority (e.g., [5-9]). However, no consensus has been so far achieved on the dimensions that characterize the openness of innovation (e.g., [10]), the approach to be adopted to measure it (e.g., [11-13]), and the unit of analysis to be considered (e.g., [14]).

Most approaches measure the openness of innovation by adopting the whole organization as the unit of analysis. Although such approaches are useful for managing open innovation, they fail to consider that different projects in the same organization may well require being diversely managed in terms of openness [15]. Additionally, even in the same project, different innovation problems may require the adoption of different open innovation practices. Neglecting such aspects may inhibit a full understanding of successful open innovation management. For such a reason, some scholars call for a shift in the study of open innovation management: from the organization to the project or even the micro-level unit of analysis, e.g., the specific problems within a project [12,14-18]. However, as mentioned in [15], studies at such units of analysis are "surprisingly" rare. Moreover, to our knowledge, in the literature, no openness measurement approach consistent with the micro-level unit of analysis has been so far proposed. 
This study discusses an approach, named Aggregative Technique for Openness Measurement (ATOM), to assess the openness of innovation at the micro-level of analysis. The approach, rooted in the concept of knowledge supply (KS), i.e., any external provision of knowledge needed in an innovation project, allows the measurement of innovation openness by looking at the number of the involved KSs, their criticality, and the open innovation practices adopted to manage them.

The paper contributes to research on the measurement of open innovation. In particular, besides shedding some light on the dimensions that characterize the openness of innovation and open innovation practices, the paper proposes an approach to measuring innovation openness at the micro-level unit of analysis, thus addressing the limits of the approaches that adopt a more aggregated unit of analysis. The paper also has some managerial and policy implications. ATOM can indeed be used by managers to identify critical KSs and support them in the assessment of the openness of single innovation practices. As for the policy implications, it is important to remark that innovation is crucial to addressing sustainability grand challenges (e.g., [19-21]). Due to their complexity, such challenges cannot be addressed by actions of individuals or single organizations alone; rather, they require collaborative and orchestrated efforts to harness innovation synergies [22]. In an era characterized by proliferating open innovation practices, the results of the paper could be used by policy makers to develop policy instruments and measures as well as funding schemes to foster and facilitate such collaborative efforts [21].

The paper is structured as follows. Section 2 illustrates the main approaches to measuring open innovation and classifies them based on the adopted level of analysis. In Section 3, we define the building blocks of ATOM, which are illustrated in Section 4. In Section 5, we show how the approach can be applied to a real innovation project. Results are discussed in Section 6. Finally, in Section 7, we point out the research and managerial implications of the study and propose future research avenues.

\section{Approaches to Analyzing and Measuring the Openness of Innovation}

Open innovation has received considerable scholarly attention over the last decade and has become a mainstream phenomenon in the current business landscape and socioeconomic scenario [15]. As it harnesses innovation synergies, besides being crucial to addressing the sustainability grand challenges (e.g., [21-23]), open innovation is playing an important role in recovering from the consequences of the coronavirus [24,25]. Some important developments in the battle against coronavirus (e.g., the mobilization of scientists, companies, and governments in the initiatives aimed at finding effective responses to the virus or the sharing of information on the virus spread and the human responses to public health measures) have openness in common. Several organizations leverage the human and physical capital that is available and already used in other places in the world. That permits faster learning and progress against the disease.

Scholars have proposed different operationalizations of the concept of innovation openness (or openness degree) also based on the level of analysis adopted in their studies, e.g., organization, innovation project, or more specific units such as the single provision of knowledge needed to develop an innovation $[8,26,27]$. The choice of the level of analysis, in turn, depends on the meanings attached to "open innovation" (for a list of definitions, the reader is referred to, e.g., [28]). For example, in his seminal works [29,30], Chesbrough discusses open innovation in terms of the high-level strategy organizations adopt to manage innovation. Such a meaning is at the root of the studies that adopt the organization as their unit of analysis. On the other hand, defining open innovation as "a distributed innovation process", Chesbrough and Bogers [31] suggest the adoption of another level of analysis (e.g., single innovation project) to measure open innovation.

The main approaches-classified based on the unit of analysis adopted-are reported below. 


\subsection{The Organization as Unit of Analysis}

The organization as a whole is the unit of analysis predominantly adopted for measuring open innovation [6]. In most cases, the openness degree of an organization is operationalized based on two drivers, i.e., the number and relevance of collaborations established with external partners. Laursen and Salter [13] assume that the higher the number of knowledge sources that an organization relies upon in the innovation activities (external search breadth), the more open the organization; similarly, the higher the extent to which an organization draws deeply to external sources (external search depth), the more open the organization itself. Most of the measurement approaches that have been developed afterwards (e.g., [32,33]) are rooted in Laursen and Salter's. For instance, in [26], the openness degree is assessed based on (i) the partner variety, i.e., the number/type of partners, and (ii) the innovation funnel openness, i.e., the number/type of phases of the innovation process that the organization opens to external contributions. As both variables can assume two values, namely low or high, four models to manage innovation are discussed.

Partially revising Laursen and Salter's breadth concept, Huang and Rice [34] identify 11 different kinds of knowledge source, and state that the higher the variety of sources an organization recurs to, the higher its openness. Spithoven et al. [35] measure the openness of innovation by a composite indicator that takes into account four open innovation practices, i.e., search strategy, external R\&D, cooperation, and protection. For each practice, several components are identified (e.g., in the case of protection, four different measures are listed, namely patents, industrial designs, trademarks, and copyrights): the higher the number of adopted components, the higher the openness of the organization with respect to that practice. Another composite indicator is proposed in [36], where the openness degree is measured as the quadratic mean of four figures, namely cost ratio (open innovation costs divided by total $R \& D$ expenditures), revenue ratio (open innovation revenues divided by total revenues), addition ratio (additions from open innovation divided by total intangibles), and disposal ratio (disposals from open innovation divided by total intangibles).

Yun et al. [37] propose to analyze and assess the openness of innovation based on what they define as the ratio of open innovation (number of patents applied by a company with external organizations divided by the total number of patents applied by that company) and the intensity of open innovation (number of applicants at the firm divided by the number of patent applications at the firm).

Finally, De Araújo Burcharth et al. [38] identify 11 practices and assume that more open organizations implement a higher number of practices. A similar perspective, though considering a different list of practices, is adopted in [39,40].

\subsection{The Innovation Project as Unit of Analysis}

Some scholars argue that the measurement of innovation openness carried out at the organization level could be misleading, because such an aggregate unit of analysis does not allow any single innovation project to be characterized. Accordingly, they adopt the innovation project as the unit of analysis (e.g., [8,14,15,41]. As discussed in [14], "switching the unit of analysis from the firm to the R\&D project level enables a more precise estimation of the open innovation performance relationship, as well as an opportunity to identify and study a new set of factors, which are only available at the project level, that moderate this relationship". Similar considerations, though aimed at studying the drivers to collaborate with specific knowledge sources (i.e., scientific institutions), are reported in [42]. Du et al. [14] measure the "open innovation partnership", which is given a value of 1 if collaborations with either a science-based (universities and knowledge institutes) or market-based partner (customers and suppliers) are involved within the innovation project, and 0 otherwise.

Knudsen and Mortensen [8] characterize the openness of a given new product development project through a bi-dimensional Boolean model, based on the reliance on both 
external and internal resources, thus identifying four types of innovation. Specifically, they mean by "open innovation" the "utilization of both internal and external sources".

Hsieh and Tidd [10] measure the openness degree of an organization at the level of single project by considering the intensity of interactions and the richness of the knowledge sharing mechanisms, rather than merely leveraging on the number and type of external relationships.

\subsection{Micro-Level Units of Analysis}

Based on the same arguments mentioned in Section 2.2, open innovation is also studied by adopting micro-level units of analysis, e.g., the individuals' choices and behaviors, what have been defined as "micro-foundations" of open innovation [18]. In particular, by drawing on the experiences of R\&D professionals, Salter et al. [18] propose a range of practices to make organization personnel better equipped to undertake effective external engagement. Dahlander et al. [16] investigate whether the innovativeness of individuals belonging to a large global company is affected by their search behavior (expressed in terms of intensity of internal and external search breadth) and the attention they pay to internal and external sources (expressed in terms of the time spent per single source).

In [12], the innovation problem is adopted as the unit of analysis, and a possible match between innovation problem types (classified based on complexity and hiddenness of dispersed knowledge) and governance forms is discussed. Specifically, four categories of open innovation governance forms (i.e., markets, partnerships, contests and tournaments, and user or community innovation) and two internal innovation governance forms, namely authority and consensus-based hierarchy, are identified and discussed.

Finally, Refs. [43-45] argue that the openness of innovation should be measured by examining each knowledge supply (KS) and assessing its criticality degree, namely a measure of its relevance for that innovation project.

We believe that the measurement of innovation openness carried out at the organization or project level, even if useful, could be misleading. In a specific innovation project, different open innovation practices can be and are usually adopted. The adoption of a broad unit of analysis may then prevent a full comprehension of successful open innovation management. However, as discussed in this section, to our knowledge, no open innovation measurement approach consistent a with micro-level unit of analysis has been so far proposed in the literature. In particular, as in [43-45], we identify the KS as our unit of analysis. By using arguments analogous to those proposed by [12] to justify the choice of innovation problems as units of analysis, we observe that any innovation project in general requires several KSs. Each KS represents a "managerially relevant" and "practical" unit of analysis at the micro-level, based on which the open innovation practices are defined. By characterizing the diverse KSs in terms of openness and relevance, the degree to which a specific innovation project is open or closed can be defined.

\section{Building Blocks of the Proposed Approach}

This paper proposes a novel approach to measuring the openness of innovation at a micro-level unit of analysis.

We focus on inbound open innovation, namely the enrichment of an organization's knowledge through the integration of external knowledge [46]. Consistently with the definition of open innovation reported in [31], we assume that such an integration purposively occurs by the means of knowledge supplies. Each supply is managed by adopting a more or less open, innovation practice. The description of knowledge supplies and open innovation practices is built on what is proposed in [43,45,47], to which the reader is referred for a deeper discussion. In Sections 3.1 and 3.2, we provide our description of the concepts. The revisions we made and their rationale are discussed in Appendix A.

As to openness, diverse meanings of the concept are discussed in the literature (e.g., $[45,48,49])$. This paper is rooted in one of them: specifically, we assume that the practices usually adopted to manage KSs within the open-source community are the best 
example of (completely) open practices. The development model adopted within such a community has been deeply studied in the literature (e.g., [50-52]). Benkler and Nissenbaum define it as a private-collective innovation model, a third innovation model in between the private and the public models [53]. Open-source software developers indeed share the code often written for personal use and collectively contribute to its development and improvement, typically in exchange for immaterial rewards, such as social recognition, good reputation, and learning opportunities.

\subsection{Knowledge Supply}

A knowledge supply (KS) is any provision of knowledge that is relevant for developing an innovation. A KS is entirely described by the following four attributes:

- The knowledge recipient is the actor who receives and exploits knowledge in a specific innovation project. The knowledge recipient may be an individual (e.g., a given employee) or a team (e.g., the R\&D department or the project team) belonging to the organization that started the project.

- The knowledge source is any individual, group, organization, or entity that provides the recipient with knowledge. Knowledge sources may be internal or external to the organization. In the former case, they include other members of the same organization who share proposals, ideas, and studies with the knowledge recipient. As mentioned, this study only considers external knowledge sources (e.g., suppliers, customers, competitors, public and private research institutions).

- $\quad$ The knowledge kind characterizes the nature of the provided knowledge (Table 1).

- The supply type describes any KS in terms of performance impact and supply risk. The former depends on three factors, namely economic (e.g., innovation cost and profitability), competence (competitive advantage achieved by the organization and ability to acquire new knowledge), and image (effect that the organization may obtain from the KS, e.g., in terms of reputation) factors. The supply risk depends on two factors, namely the supply market characteristics (e.g., the existence of entry barriers) and environmental uncertainty (e.g., frequency of changes in laws or regulations). Table 2 reports the dimensions that describe the supply type, which revises the ones proposed in [43] so as to make them scalable and adaptable to different innovation contexts.

Table 1. Dimensions for the knowledge kind.

\begin{tabular}{cc}
\hline Name & Description \\
\hline Certainty (CE) & $\begin{array}{c}\text { Knowledge recipient's level of confidence on validity of the knowledge } \\
\text { Extent to which the knowledge is preserved from change and does not } \\
\text { need to be updated }\end{array}$ \\
$\begin{array}{c}\text { Stability (ST) } \\
\text { Usability (US) }\end{array}$ & $\begin{array}{c}\text { Ease in using the provided knowledge by the knowledge recipient } \\
\text { Expertise embodied in knowledge }\end{array}$ \\
$\begin{array}{c}\text { Applicability (AP) } \\
\text { Originality (OR) }\end{array}$ & $\begin{array}{c}\text { How broadly the knowledge can be applied (locally or globally to other } \\
\text { organizations' activities or processes) }\end{array}$ \\
Onerousness (ON) & The degree of uniqueness or novelty of the provided knowledge \\
Direct and indirect costs needed to adopt the provided knowledge
\end{tabular}

Table 2. Dimensions for the supply type.

\begin{tabular}{cc}
\hline First Tier Dimension & Second Tier Dimension \\
\hline Performance impact & Economic factors (EF) \\
& Competence factors (CF) \\
Image factors (IF) \\
\hline Supply risk & Supply market characteristics (SC) \\
& Environmental uncertainty (EU) \\
\hline
\end{tabular}




\subsection{Innovation Practice}

An innovation practice (IP) results from a set of decisions concerning the management of each KS. Table 3 summarizes the dimension of IPs and the attendant values.

Table 3. Dimensions of the IPs and their possible values.

\begin{tabular}{|c|c|c|}
\hline Dimension & Definition & Values \\
\hline Access mode & $\begin{array}{l}\text { The recipient's choice to/not to limit } \\
\text { the search of the knowledge source } \\
\text { among pre-qualified actors }\end{array}$ & $\begin{array}{l}\text { - Closed (0), if the KS is provided by an ad-hoc } \\
\text { selected source (e.g., a consultant). } \\
\text { Open (1), if any possible knowledge source can } \\
\text { access to the knowledge recipient's request } \\
\text { (e.g., a request posted on a knowledge } \\
\text { broker website). }\end{array}$ \\
\hline Degree of formalization & $\begin{array}{l}\text { The extent to which the } \\
\text { communication between knowledge } \\
\text { source and recipient is based on } \\
\text { standards, protocol, and procedures }\end{array}$ & $\begin{array}{l}\text { - High (0), if the KS is provided in a formalized } \\
\text { mode (e.g., a written report based on } \\
\text { a template) } \\
\text { Low (1), if the KS is provided in an informal } \\
\text { mode (e.g., unstructured conversations). }\end{array}$ \\
\hline Incentives & $\begin{array}{l}\text { The driver for the knowledge source } \\
\text { to take part in the KS }\end{array}$ & $\begin{array}{l}\text { - Pecuniary (0), if the KS is provided against } \\
\text { payment (e.g., in the case of consultants hired } \\
\text { by the recipient). } \\
\text { - Non-pecuniary (1), if the KS is provided for } \\
\text { free (e.g., in the case of open source software } \\
\text { development projects) }\end{array}$ \\
\hline Interaction mode & $\begin{array}{l}\text { The way the knowledge recipient and } \\
\text { the knowledge source interact }\end{array}$ & $\begin{array}{l}\text { - Static (0), if the knowledge is merely } \\
\text { transferred (e.g., by means of a } \\
\text { technical report). } \\
\text { Dynamic (1), if the KS involves a process in } \\
\text { which the recipient learns as well (e.g., in the } \\
\text { case of involvement in a common } \\
\text { research project) }\end{array}$ \\
\hline Locus of control & $\begin{array}{c}\text { The actor who makes decisions on } \\
\text { the KS }\end{array}$ & $\begin{array}{l}\text { In the hands of the knowledge recipient (0), } \\
\text { if the latter rules any aspect of the KS. } \\
\text { In the hands of the knowledge source (1), } \\
\text { if he/she oversees any decisions. }\end{array}$ \\
\hline Coordination mechanism & $\begin{array}{l}\text { Mechanism adopted to manage the } \\
\text { interdependence between knowledge } \\
\text { recipient and source }\end{array}$ & $\begin{array}{l}\text { - Programming (0), if tasks, deliverables, and } \\
\text { time schedule are detailed in advance. } \\
\text { Feedback (1), if tasks, deliverables, and time } \\
\text { schedule are continuously adjusted based upon } \\
\text { ideas and discoveries that emerge during } \\
\text { the KS. }\end{array}$ \\
\hline Output accessibility & $\begin{array}{c}\text { The existence of limitations to access } \\
\text { or adopt results of the KS }\end{array}$ & $\begin{array}{l}\text { - Closed (0), if results of KS are private or subject } \\
\text { to intellectual property rights (e.g., copyright, } \\
\text { patents, or licenses). } \\
\text { - Open (1), if they are made accessible or usable } \\
\text { by anyone (e.g., some governmentally funded } \\
\text { research programs). }\end{array}$ \\
\hline Relationship form & $\begin{array}{l}\text { The kind of formal relationships } \\
\text { between the innovating organization } \\
\text { and the knowledge source }\end{array}$ & $\begin{array}{l}\text { - Pure market (0) (e.g., consultancy agreement } \\
\text { ruled by a contract) } \\
\text { Partnership (1) (e.g., joint venture, } \\
\text { equity investment). }\end{array}$ \\
\hline
\end{tabular}

For the sake of simplicity, we hypothesize that all the dimensions may take two values, although we are aware that some dimensions might also assume intermediate values (for instance, for the access mode, the knowledge recipient might also release an open call limited to a set of potential knowledge sources that have been pre-qualified).

Each value associated with every dimension that defines an IP is coded as 1 or 0 . In particular, $1(0)$ implies that the knowledge source is (is not) free to take part to the 
innovation project; is driven by not pecuniary (pecuniary) incentives; plays (does not play) a more active role while defining the features of the knowledge that is provided; is (is not) able to exploit the provided output in different contexts; and so on. Consistently with our definition of the concept of openness (as discussed at the beginning of Section 3), we assume that the greater the number associated with a specific value for a given dimension, the more open the innovation practice with respect to that dimension.

\section{The Aggregative Technique for Openness Measurement (ATOM)}

In this section we propose a novel approach, called Aggregative Technique for Openness Measurement (ATOM), to measure the openness of innovation. The methodology is rooted in the assumption that measuring the openness of innovation entails not only the measurement of the number of KSs, but also the relevance (or criticality) of such supplies as well as the openness degree of the specific IPs adopted to manage them.

\subsection{Openness Degree of an IP}

As stated in Section 3.2, each IP consists of eight dimensions, whose possible values are listed in Table 3. Therefore, to assess the openness degree of an IP, the following rule is proposed: the greater the arithmetic mean of the dimension values, the more open the innovation practice. Hence, the openness degree of an innovation practice ranges in the $[0,1]$ interval, higher values meaning a more open practice.

\subsection{Criticality of $K S S$}

The criticality of a KS assesses the relevance of that supply for a given innovation. We assume that a KS is critical if both its knowledge kind and its supply type are critical as well. By revising the methodology proposed in $[43,45]$, we measure the criticality of a KS by the three-step procedure reported below.

First step. The knowledge kind characterizes the nature of the knowledge provided within the KS. Its criticality can be assessed with respect to seven dimensions, as listed in Table 1. To this aim, the knowledge recipient preliminarily implements a pairwise comparison procedure [54] among these dimensions and calculates their weight through the logarithmic least squares method [55], as:

$$
w_{i}=\frac{\sqrt[n]{\prod_{j=1}^{n} a_{i j}}}{\sum_{t=1}^{n}\left(\sqrt[n]{\prod_{j=1}^{n} a_{t j}}\right)}, \forall i=1, \ldots, n
$$

where $n=7$ is the number of dimensions compared, $w_{i}$ is the weight of the $i$-th dimension, and $a_{i j}$ is the dominance index of the $i$-th dimension over the $j$-th one, expressed in accordance with the fundamental scale of judgment [54]. An explanation of Formula (1) is reported in the Appendix B. Then, the knowledge recipient rates each KS with respect to every knowledge kind dimension: it is convenient to assume the same scale for each dimension, for instance the $(0,1)$ interval. The criticality of the knowledge kind for a KS is the weighted average of the knowledge kind attribute ratings as assigned by the knowledge recipient.

Second step. The knowledge recipient assesses the criticality of the supply type as well, with respect to the dimensions listed in Table 2. Since these dimensions are structured in a hierarchy, we propose to weight them by Analytic Hierarchy Process [54]. The knowledge recipient compares pairwise the dimensions at the first level and calculates their weights using the logarithmic least squares method. Then, he/she iteratively implements the pairwise comparison procedure for each group of dimensions having the same parent dimension, and derives their local weights. Finally, he/she calculates the global weight of each dimension as the product of its local weight and the global weight of the parent dimension. Moreover, the knowledge recipient rates each KS with respect to every supply type dimension. The criticality of the supply type for a KS is the weighted sum of its ratings. 
Third step. The criticality of the KS is measured as the product between the criticalities of the knowledge kind and the supply type.

\subsection{Openness of Innovation}

We assume that the openness of innovation depends on both the criticality of all the KSs that are required to carry it out and the openness degree of the attendant IPs. More precisely, the openness of an innovation that resorts to many KSs, each managed according its own IP, is calculated by multiplying the criticality of every KS by the openness degree of the attendant IP, and summing them up.

Figure 1 represents the main elements used in the Aggregative Technique for Openness Measurement, and shows how the openness of innovation reflects the openness degree of each KS, which in turn depends on both the inherent characteristics of the KS (i.e., nature of knowledge provided as well as performance impact and supply risk associated with it) and the way in which the KS is managed (which determines the openness degree of the IP).

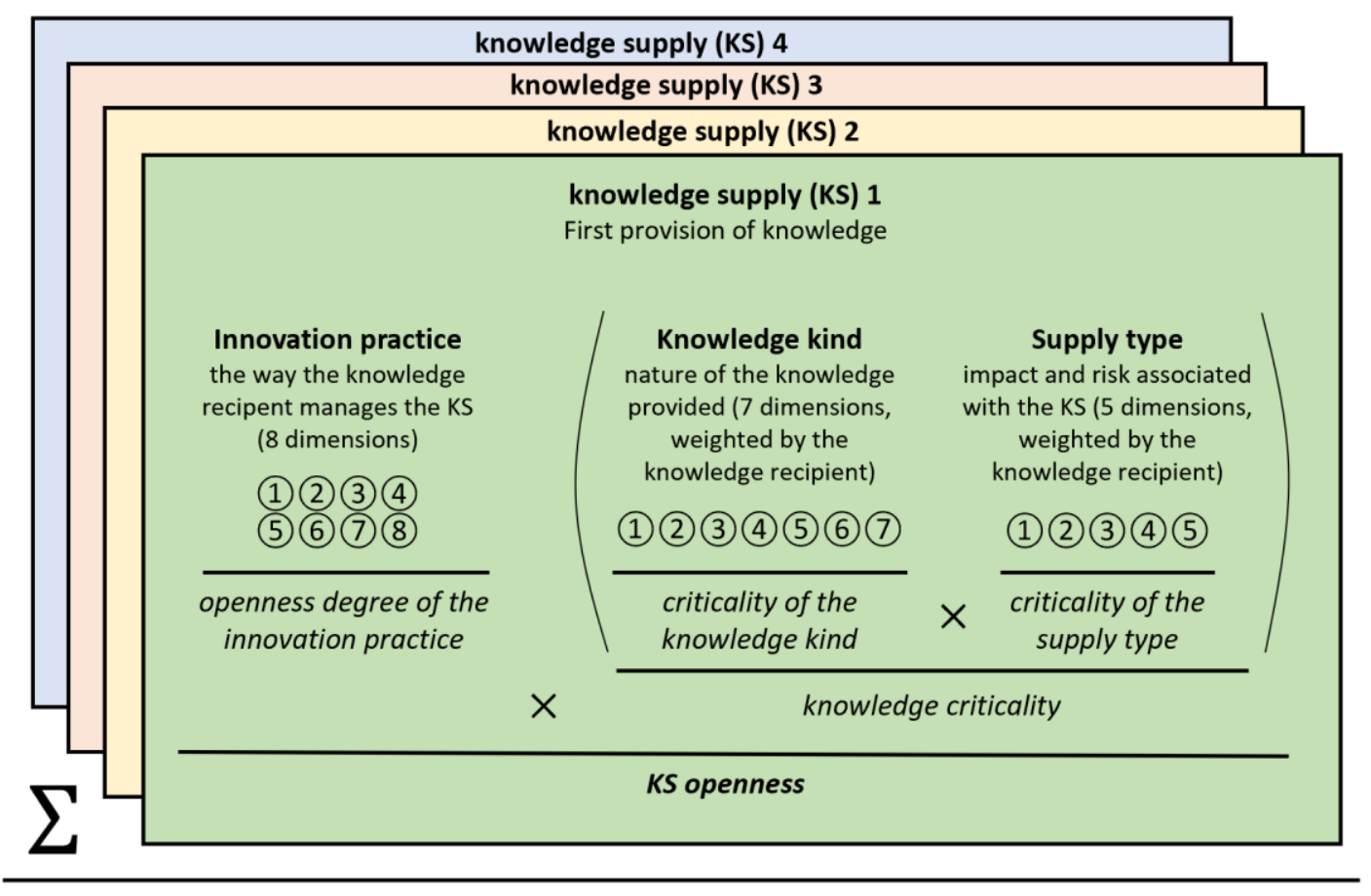

openness of innovation

Figure 1. Graphical representation of the Aggregative Technique for Openness Measurement (ATOM). Each layer represents a different KS. The openness of innovation depends on each KS openness degree, which in turn descends from both the openness degree of the innovation practice and the knowledge criticality. The former, based on eight dimensions, describes the way in which the knowledge recipient manages the KS. The latter derives from the criticality of the knowledge kind (seven dimensions, weighted by the knowledge recipient, that describe the nature of the knowledge provided) and the criticality of the supply type (five dimensions, weighted by the knowledge recipient, that describe the performance impact and supply risks associated with the KS).

\section{Application}

In this section, we show how the proposed approach can be applied. The application was mainly aimed at identifying, through the implementation on real innovation project, possible criticalities and aspects to be improved. The use of a confirmation phase is consistent with the model of theory building adopted in applied disciplines, as described in [52-57]. According to them, the confirmation phase follows the conceptual development (whose purpose is the development of an initial conceptual framework that contains the key elements of the issue, problem, or phenomenon) and the operationalization (which aims at converting the conceptual framework to measurable elements): it involves the 
application of the results of the previous phases to real cases, to confirm (or disconfirm) the framework. In this case, it consists in the adoption of the proposed measurement approach in a real innovation project.

The specific application deals with a project financed by the Italian Ministry of Instruction, University, and Research and called "Decision support system for maritime environment emergency management". The project aimed at developing a new generation console to support rescue coordination centers during maritime search and rescue missions. The project involved three partners, namely: Leonardo S.p.A., a multinational company specialized in aerospace, defense, and security; Codin S.p.A., an Italian IT company; and Politecnico di Bari, a public Italian university. The project, concluded in 2015, had a budget of about 8.5 million euros and a duration of three years. Several knowledge supplies were involved. However, for illustrational purposes, we illustrate the application restricted to a subset of activities (Case 1) that involved two knowledge recipients, named A and B, which recurred to four and three KSs, respectively. The KSs are denoted as KS1 to KS4 for the knowledge recipient A, and as KS5 to KS7 for the knowledge recipient B.

We also ad-hoc developed a Case 2, whose knowledge recipients and KSs are in common with Case 1 (thus, the values of knowledge criticalities in both cases are the same), but the adopted IPs are different. Therefore, their openness degrees are different from the ones of Case 1. Both cases and attendant insights are reported below.

\subsection{Case 1}

Tables 4 and 5 illustrate the values for the dimensions that characterize the IPs that the knowledge recipients A and B, respectively, adopted to manage the KSs. The attendant openness degrees have been calculated based on the procedure described in Section 4.1.

Table 4. Case 1: characterization of the KSs for the knowledge recipient A, and attendant openness degrees.

\begin{tabular}{|c|c|c|c|c|}
\hline Dimension & KS1 & KS2 & KS3 & KS4 \\
\hline Access mode & closed & closed & closed & open \\
\hline Degree of formalization & low & high & low & low \\
\hline Incentives & nonpecuniary & pecuniary & nonpecuniary & pecuniary \\
\hline Interaction mode & static & static & dynamic & dynamic \\
\hline $\begin{array}{l}\text { Locus of control } \\
\text { Coordination } \\
\text { mechanism }\end{array}$ & $\begin{array}{l}\text { knowledge recipient } \\
\text { feedback }\end{array}$ & $\begin{array}{l}\text { knowledge source } \\
\text { programming }\end{array}$ & $\begin{array}{c}\text { knowledge recipient } \\
\text { feedback }\end{array}$ & $\begin{array}{c}\text { knowledge source } \\
\text { feedback }\end{array}$ \\
\hline Output accessibility & closed & closed & closed & open \\
\hline Relationship form & partnership & pure market & partnership & partnership \\
\hline Openness degree & 0.500 & 0.000 & 0.625 & 0.750 \\
\hline
\end{tabular}

Table 5. Case 1: characterization of the KSs for the knowledge recipient B, and attendant openness degrees.

\begin{tabular}{|c|c|c|c|}
\hline Dimension & KS5 & KS6 & KS7 \\
\hline Access mode & closed & open & closed \\
\hline Degree of formalization & high & high & high \\
\hline Incentives & pecuniary & pecuniary & nonpecuniary \\
\hline Interaction mode & static & dynamic & dynamic \\
\hline Locus of control & knowledge source & knowledge recipient & knowledge recipient \\
\hline Coordination mechanism & feedback & feedback & feedback \\
\hline Output accessibility & closed & closed & closed \\
\hline Relationship form & pure market & pure market & partnership \\
\hline Openness degree & 0.250 & 0.375 & 0.500 \\
\hline
\end{tabular}

To assess the criticality of the KSs, the procedure described in Section 4.2 has been implemented. The knowledge recipient A at first (i) derives the weights of the knowledge kind dimensions via pairwise comparisons, (ii) rates each KS (from KS1 to KS4) as for every 
dimension, and (iii) derives the criticality of the knowledge kind as a weighted sum of its ratings. Results of steps (ii) and (iii) are summarized in Table 6, which reports the weights of each dimension of the knowledge kind, as calculated via pairwise comparison procedure. Then, the knowledge recipient A (i) assesses via pairwise comparisons the importance of the supply type dimensions for each KS, (ii) rates each KS with respect to every dimension, and (iii) derives the criticality of the supply type for it as a weighted sum of the ratings so obtained. Results of steps (ii) and (iii) are reported in Table 7, which also summarizes the weights of each dimension of the supply type, as calculated via pairwise comparison procedure. Finally, for each KS, the product between the criticality of the knowledge kind and the criticality of the supply type gives the criticality of the KS. Table 8 reports the results for all the KSs related to the knowledge recipient A. They show that the KS with the highest criticality is KS1, followed by KS3 and KS2, whereas KS4 is the less critical.

Table 6. Criticality of the knowledge kind for the KSs related to the knowledge recipient A.

\begin{tabular}{ccccccccc}
\hline $\begin{array}{c}\text { Dimension of the } \\
\text { Knowledge Kind }\end{array}$ & CE & ST & US & PR & AP & OR & ON & $\begin{array}{c}\text { Criticality of the } \\
\text { Knowledge Kind }\end{array}$ \\
\hline Weight & 0.107 & 0.035 & 0.181 & 0.391 & 0.199 & 0.043 & 0.044 & \\
\hline KS1 & 0.90 & 0.25 & 0.80 & 0.90 & 0.55 & 0.90 & 0.30 & 0.763 \\
KS2 & 0.40 & 0.20 & 0.20 & 0.60 & 0.20 & 0.15 & 0.50 & 0.389 \\
KS3 & 0.10 & 0.60 & 0.60 & 0.30 & 0.85 & 0.50 & 0.80 & 0.483 \\
KS4 & 0.20 & 0.40 & 0.35 & 0.30 & 0.40 & 0.20 & 0.20 & 0.313 \\
\hline
\end{tabular}

Table 7. Criticality of the supply type for the KSs related to the knowledge recipient A.

\begin{tabular}{|c|c|c|c|c|c|c|}
\hline \multirow{3}{*}{$\begin{array}{c}\text { First Tier Dimension } \\
\text { weight } \\
\text { Second Tier } \\
\text { Dimension }\end{array}$} & \multicolumn{3}{|c|}{ Performance Impact } & \multicolumn{2}{|c|}{ Supply Risk } & \multirow{5}{*}{$\begin{array}{l}\text { Criticality of the } \\
\text { Supply Type }\end{array}$} \\
\hline & \multirow[b]{2}{*}{ EF } & \multicolumn{2}{|c|}{0.750} & \multicolumn{2}{|c|}{0.250} & \\
\hline & & CF & IF & SC & EU & \\
\hline local weight & 0.443 & 0.387 & 0.169 & 0.667 & 0.333 & \\
\hline global weight & 0.333 & 0.291 & 0.127 & 0.167 & 0.083 & \\
\hline KS1 & 0.15 & 0.75 & 0.80 & 0.80 & 0.30 & 0.528 \\
\hline KS2 & 0.90 & 0.30 & 0.60 & 0.10 & 0.35 & 0.508 \\
\hline KS3 & 0.35 & 0.75 & 0.30 & 0.60 & 0.75 & 0.535 \\
\hline KS4 & 0.10 & 0.20 & 0.50 & 0.30 & 0.20 & 0.221 \\
\hline
\end{tabular}

Table 8. Knowledge criticality for the KSs of the knowledge recipient A.

\begin{tabular}{cccc}
\hline KSs & $\begin{array}{c}\text { Criticality of the } \\
\text { Knowledge Kind }\end{array}$ & $\begin{array}{c}\text { Criticality of the } \\
\text { Supply Type }\end{array}$ & Knowledge Criticality \\
KS1 & 0.763 & 0.528 & 0.403 \\
KS2 & 0.389 & 0.508 & 0.198 \\
KS3 & 0.483 & 0.535 & 0.258 \\
KS4 & 0.313 & 0.221 & 0.069 \\
\hline
\end{tabular}

Similarly, the knowledge recipient B carries out the same calculations with reference to the KS5 to KS7 (Tables 9-11): it is noteworthy that the two knowledge recipients give different weights to the knowledge kind as well as supply type dimensions. 
Table 9. Criticality of the knowledge kind for the KSs related to the knowledge recipient B.

\begin{tabular}{ccccccccc}
\hline $\begin{array}{c}\text { Dimension of the } \\
\text { Knowledge Kind }\end{array}$ & CE & ST & US & PR & AP & OR & ON & $\begin{array}{c}\text { Criticality of the } \\
\text { Knowledge Kind }\end{array}$ \\
\hline Weight & 0.073 & 0.318 & 0.084 & 0.029 & 0.307 & 0.033 & 0.156 & \\
\hline KS5 & 0.80 & 0.20 & 0.80 & 0.30 & 0.30 & 0.75 & 0.25 & 0.354 \\
KS6 & 0.80 & 0.70 & 0.20 & 0.60 & 0.20 & 0.35 & 0.25 & 0.427 \\
KS7 & 0.30 & 0.45 & 0.40 & 0.10 & 0.40 & 0.20 & 0.70 & 0.440 \\
\hline
\end{tabular}

Table 10. Criticality of the supply type for the KSs related to the knowledge recipient B.

\begin{tabular}{|c|c|c|c|c|c|c|}
\hline \multirow{3}{*}{$\begin{array}{c}\text { First Tier Dimension } \\
\text { weight } \\
\begin{array}{c}\text { Second tier } \\
\text { dimension }\end{array} \\
\end{array}$} & \multicolumn{3}{|c|}{ Performance Impact } & \multicolumn{2}{|c|}{ Supply Risk } & \multirow{5}{*}{$\begin{array}{l}\text { Criticality of the } \\
\text { Supply Type }\end{array}$} \\
\hline & \multicolumn{3}{|c|}{0.667} & \multicolumn{2}{|c|}{0.333} & \\
\hline & EF & CF & IF & $\mathrm{SC}$ & EU & \\
\hline local weight & 0.637 & 0.258 & 0.105 & 0.750 & 0.250 & \\
\hline global weight & 0.425 & 0.172 & 0.070 & 0.250 & 0.083 & \\
\hline KS5 & 0.30 & 0.85 & 0.60 & 0.90 & 0.90 & 0.616 \\
\hline KS6 & 0.80 & 0.50 & 0.60 & 0.25 & 0.60 & 0.580 \\
\hline KS7 & 0.30 & 0.30 & 0.25 & 0.10 & 0.40 & 0.255 \\
\hline
\end{tabular}

Table 11. Knowledge criticality for the KSs of the knowledge recipient B.

\begin{tabular}{cccc}
\hline KSs & $\begin{array}{c}\text { Criticality of the } \\
\text { Knowledge Kind }\end{array}$ & $\begin{array}{c}\text { Criticality of the } \\
\text { Supply Type }\end{array}$ & Knowledge Criticality \\
\hline KS5 & 0.354 & 0.616 & 0.218 \\
KS6 & 0.427 & 0.580 & 0.248 \\
KS7 & 0.440 & 0.255 & 0.112 \\
\hline
\end{tabular}

Tables 8 and 11 show the most critical KSs. For the knowledge recipient A, the most critical knowledge supply is KS1. That is especially due to the knowledge kind criticality (0.763 in a $[0,1]$ interval), whereas the supply type criticality $(0.528$ in a $[0,1]$ interval) is lower than for KS3 (0.535). At the opposite, KS4, whose knowledge kind and supply type criticalities are both low, is not critical. Specifically, its knowledge criticality is 0.069 , about six times lower than for KS1. Irrespective of the openness degree of the attendant IP, KS4 will not significantly contribute to the openness degree of innovation. Similarly, Table 11 shows that all the KSs having B as knowledge recipient have a quite high value for the supply type criticality, but a medium-to-low knowledge criticality, ranging from 0.112 to 0.248 : for all of them, the knowledge kind, in fact, does not reach a substantial level of criticality. The innovating organization may utilize the above results to decide how to manage the different KSs, in terms of budget allocation as well as openness of the innovation practice to adopt: the higher their knowledge criticality, the higher the importance to strengthen the relationship with the knowledge supplier.

Once the openness degree and the knowledge criticality of every KS have been obtained, it is possible to calculate the openness of innovation, as described in Section 4.3, i.e., by multiplying the IP openness degree of each KS by the attendant knowledge criticality, and summing up the KSs' openness so obtained. Results, presented in Table 12, show that the openness of the considered innovation is 0.643: it is remarkable that the KS4, whose IP has the highest openness degree $(0.750)$, is not the one that contributes more in increasing the openness of innovation, due to its low knowledge criticality. The higher contribution to the openness of innovation (0.202) comes from KS1, whose openness degree is medium. As discussed above, KS1 has the higher knowledge criticality; meanwhile, KS4, whose knowledge criticality is very low, gives a negligible contribution to the openness 
of innovation, even though, based on the innovation practice adopted to manage it, the supply presents the highest openness.

Table 12. Case 1: Openness of innovation.

\begin{tabular}{cccc}
\hline KSs & IP Openness Degree & Knowledge Criticality & KS Openness \\
\hline KS1 & 0.500 & 0.403 & 0.202 \\
KS2 & 0.125 & 0.198 & 0.025 \\
KS3 & 0.625 & 0.258 & 0.161 \\
KS4 & 0.750 & 0.069 & 0.052 \\
KS5 & 0.250 & 0.218 & 0.055 \\
KS6 & 0.375 & 0.248 & 0.093 \\
KS7 & 0.500 & 0.112 & 0.056 \\
\hline
\end{tabular}

\subsection{Case 2}

We now assume that the KSs are managed in a different way: Tables 13 and 14 illustrate how the knowledge recipients A and B, respectively, arrange their IPs: all the attendant dimensions assume values as high (i.e., open) as possible, so that in case 2, all the KS have the maximum openness degree.

Table 13. Case 2: characterization of the KSs for the knowledge recipient A, and attendant openness degrees.

\begin{tabular}{|c|c|c|c|c|}
\hline Dimension & KS1 & KS2 & KS3 & KS4 \\
\hline Access mode & open & open & open & open \\
\hline Degree of formalization & low & low & low & low \\
\hline Incentives & non-pecuniary & non-pecuniary & non-pecuniary & non-pecuniary \\
\hline Interaction mode & dynamic & dynamic & dynamic & dynamic \\
\hline $\begin{array}{l}\text { Locus of control } \\
\text { Coordination } \\
\text { mechanism }\end{array}$ & $\begin{array}{c}\text { knowledge source } \\
\text { feedback }\end{array}$ & $\begin{array}{l}\text { knowledge source } \\
\text { feedback }\end{array}$ & $\begin{array}{c}\text { knowledge source } \\
\text { feedback }\end{array}$ & $\begin{array}{c}\text { knowledge source } \\
\text { feedback }\end{array}$ \\
\hline Output accessibility & open & open & open & open \\
\hline Relationship form & pure market & pure market & pure market & pure market \\
\hline Openness Degree & 1.000 & 1.000 & 1.000 & 1.000 \\
\hline
\end{tabular}

Table 14. Case 2: characterization of the KSs for the knowledge recipient B, and attendant openness degrees.

\begin{tabular}{|c|c|c|c|}
\hline Dimension & KS5 & KS6 & KS7 \\
\hline Access mode & open & open & open \\
\hline Degree of formalization & low & low & low \\
\hline Incentives & non-pecuniary & non-pecuniary & non-pecuniary \\
\hline Interaction mode & dynamic & dynamic & dynamic \\
\hline Locus of control & knowledge source & knowledge source & knowledge source \\
\hline Coordination mechanism & feedback & feedback & feedback \\
\hline Output accessibility & open & open & open \\
\hline Relationship form & pure market & pure market & pure market \\
\hline Openness Degree & 1.000 & 1.000 & 1.000 \\
\hline
\end{tabular}

It is also assumed that the recipients keep the same assessments as for both the criticalities of knowledge kinds and the criticalities of supply type, so that the knowledge criticality of KSs is the same as in Case 1 (Tables 6 and 7 for recipient A, and Tables 9 and 10 for recipient B). However, since the openness degree of the KSs is higher in Case 2 than in Case 1, the openness of innovation is higher in Case 2 than in Case 1 as well (Table 15). In this case, the highest contribution to the openness of innovation as a whole is also due 
to KS1, i.e., the supply with the highest knowledge criticality (0.403), whereas the lowest contribution is due to KS4, given that it has the lowest knowledge criticality.

Table 15. Case 2: Openness of innovation.

\begin{tabular}{lccc}
\hline KSs & IP Openness Degree & Knowledge Criticality & KS Openness \\
\hline KS1 & 1.000 & 0.403 & 0.403 \\
KS2 & 1.000 & 0.198 & 0.198 \\
KS3 & 1.000 & 0.258 & 0.258 \\
KS4 & 1.000 & 0.069 & 0.069 \\
KS5 & 1.000 & 0.218 & 0.218 \\
KS6 & 1.000 & 0.248 & 0.248 \\
KS7 & 1.000 & 0.112 & 0.112 \\
\hline
\end{tabular}

\section{Discussion}

In this section, we first comment on the results of the confirmation phase. Then, we discuss ATOM with respect to extant literature.

The confirmation phase did not highlight any specific problem. The application cases proposed in Section 5 showed that, apart from the relative onerousness of some calculations, the implementation of ATOM is straightforward.

The approach is rooted in the literature, but presents some innovative elements. As in [31], we argue that the innovation process is carried out by purposively involving knowledge flows. Based on a reasoned revision of the concepts reported in $[43,45,47]$, we characterize such flows in terms of KSs, describe the set of practices to manage each KS involved in a given innovation project, and report an approach to measuring the criticality of KSs. Additionally, as discussed in $[43,45]$, the characterization of a practice takes into account the pecuniary vs. nonpecuniary category mentioned in [31], but it is not limited to that.

As to the innovativeness of the approach, this represents the first attempt, as far as we know, to measure the openness of an innovation at a micro-level unit of analysis. The proposed Aggregative Technique for Openness Measurement, indeed, derives the openness of innovation from the openness degree of each $\mathrm{KS}$ that is relevant for developing that innovation. Each KS openness degree, in turn, is calculated by considering not only the openness of the specific innovation practice that the knowledge recipient adopts to manage that KS, but also the inherent criticality of that supply. The way we measure the openness of the specific innovation practices adopted represents another element of innovativeness of the present study. As mentioned, most open innovation measurement approaches are rooted in the model proposed in [13], which adopts an organization-level unit of analysis and measures the openness of an organization's external search strategies based on the concepts of breadth and depth. In particular, the model above defines the breadth as "the number of sources or search channels that firms rely upon in their innovative activities" and the depth as "the extent to which firms draw deeply from the different external sources or search channels". However, in our opinion, such definitions leave a couple of questions unsolved. First, the concept of depth is not clearly defined, and that may generate problems in the operationalization stage. Moreover, once the knowledge sources are identified in terms of number and degree of "use", the openness of the organization is given, irrespective of the mode adopted to manage the relationship with each source. On the contrary, our approach clearly (i) defines the dimensions of the IPs adopted to manage the KSs (including dimensions that are neglected in other measurement approaches) and (ii) measures the openness of innovation based on the values each dimension assumes. That means that, once the KSs are identified, the openness of innovation changes if the practices adopted to manage those $\mathrm{KS}$ s are modified (as illustrated in Case 2 vs. Case 1). The clear characterization of the IPs allows the openness of single innovation projects to be assessed. Although we do not pretend to present an exhaustive set of dimensions to 
characterize the IPs, we believe that the set (i) may be useful reference to measure the openness of innovation in a more harmonized way and (ii) is scalable, meaning that it could be easily integrated with other dimensions, if appropriate.

From a managerial and policy perspective, as illustrated in Cases 1 and 2, the proposed approach contributes to making the concept of innovation openness less fuzzy by clearly identifying the dimensions to be considered to make each IP more (or less) open. Since each step of the proposed approach is clearly described, it can be easily adopted by managers. It may also be useful to identify the most critical provisions of knowledge involved in innovation development and prioritize the innovating organization's effort to manage the attendant KSs.

The methodology can be adopted ex-ante to carry on what-if analyses and scrutinize how changes in innovation practices, i.e., the way KSs are managed, might affect the openness of innovation. Finally, managers can use the approach to keep track of the innovation project in terms of KSs and IPs so as to allow ex-post learning. The approach does not support managers in the identification of the most appropriate practice to adopt in a specific innovation context, a goal that is out of the scope of this paper. We call for more studies to address such a relevant issue.

Policy-makers interested in promoting collaboration among different business entities, in a single industry if not in the whole economic system, and enticing innovation-oriented organizations' mutual relationships, may adopt the proposed methodology to explore the most relevant knowledge flows, as a guidance for resource allocation and to develop funding schemes that are consistent with their strategic goals.

\section{Conclusions}

In the last decades, increasing attention has been devoted to open innovation from both scholars and practitioners. However, despite the plethora of studies, it is not clear whether and under which conditions open innovation is beneficial to organizations. To address such questions, the measurement of the openness of innovation is essential.

In this paper, we first discuss the approaches to analyzing and measuring innovation based the unit of analysis adopted. Then, after highlighting the limits of the approaches developed at the organization- and project-level unit of analysis, we propose a novel approach, named Aggregative Technique for Openness Measurement (ATOM), to measure the openness of an innovation, at a micro-unit level of analysis. ATOM is based on the number and the criticality of the knowledge supplies involved in an innovation project and the openness degree of the practices adopted to manage them. As prescribed by the confirmation phase within the theory building model, the approach has been applied. Though restricted on two cases to manage a single innovation project, the analysis has shown that, apart from the relative onerousness of some calculations, the application of ATOM is straightforward. Moreover, by comparing our approach with extant literature, we derived some insights. Our approach (i) clearly defines the dimensions of the innovation practices adopted to manage the KSs and (ii) measures the openness of innovation based on the openness of the practices adopted and the criticality of each knowledge supply involved in the innovation project. Hence, it contributes to clarifying the concept of innovation openness. Additionally, to our knowledge, it represents the first attempt to measure it at a micro-unit of analysis. It thus contributes to the literature by highlighting the importance of micro-foundations in open innovation management whose relevance has been emphasized in recent studies, e.g., $[15,18]$. Finally, our approach takes into account dimensions-e.g., coordination mechanisms and relationship form, locus of control, and accessibility of the output-discussed in the extant literature (e.g., [27,58-60]), which, to our knowledge, none of other measurement approaches have so far considered all at once.

The paper also has some relevant practical implications. From a managerial perspective, the approach may be useful for practitioners involved in innovation development, as it proposes a straightforward procedure to (i) identify and measure the criticality of knowledge supplies, (ii) assess the openness of innovation practices, and (iii) support 
ex-post learning on the way an innovation project was managed. Recent research has also stressed the importance of open innovation to address sustainability challenges and highlighted the need for new policy tools (e.g., measures and funding schemes) to foster and facilitate the adoption of open approaches to develop sustainable innovations. The results of the papers could be used by policy makers to develop such tools [21].

The proposed approach presents some limitations as well, which may open new research avenues. First, as discussed, the main limitation is associated with the relative onerousness of calculations: though simple, they require time and effort that increase with the number of the KSs involved in the considered innovation project. On the other hand, we live in the age of artificial intelligence; thus, such a limit would be quite easily addressed even for large real projects. Future research would include the development of a software solution enabling companies to measure the openness degree associated with each KS as well as an entire project. Second, we are aware that the proposed set of dimensions relevant to operatively managing the KSs might not be considered exhaustive: the literature on collaboration, which not only concerns innovation, is indeed extremely wide. Moreover, new dimensions could emerge as relevant in the future because of a change in the economic environment. Yet, the approach is scalable, and thus it could be easily integrated with other possible dimensions. In this respect, our contribution is in the sense of stressing the importance of identifying a shared set of dimensions to characterize IPs. Third, for the sake of simplicity, for each dimension of an IP, two possible values are considered, which may oversimplify reality. Defining a complete set of values for each dimension was outside the scope of this paper; nonetheless, ATOM has been designed so that a higher granularity might be adopted where appropriate. Fourth, ATOM aggregates different measures, thus inevitably neglecting some information. However, as discussed in [35], the use of composite measures has proven to be highly useful in a wide range of internationally renowned research contexts. In addition, the information behind the composite indicator can regardless be utilized for purposes such as ex-post learning. Fifth, ATOM applies arithmetic and weighted means on ordinal, rather than cardinal, variables. The appropriateness of statistical manipulation for such variables is controversial and has fed a debate among scholars for decades [61]; nonetheless, such a manipulation has been extensively and successfully adopted in various domains-e.g., psychology [62], marketing [63], and medicine [64] —and specifically in the field of open innovation (e.g., [31,34,37]). Furthermore, the proposed approach has been applied for confirmative purposes to a real product innovation project: although no specific criticality was aroused, it might be beneficial to apply it to different cases, such as process or organizational innovation. A possible avenue for further research includes the application to a larger and more heterogeneous set of cases. An additional research direction concerns the model calibration, given that the considered application has been mainly aimed at identifying possible criticalities in the framework, as previously developed and operationalized.

We hope that our contribution will stimulate scholars to debate further approaches to measure open innovation at a micro-level unit of analysis.

Author Contributions: Conceptualization: all authors; methodology: all authors; validation: N.B. and B.S.; data curation: N.B.; writing—original draft preparation: all authors; writing—review and editing: all authors; visualization: N.B.; supervision: P.P. All authors have read and agreed to the published version of the manuscript.

Funding: This research received no external funding.

Institutional Review Board Statement: Not applicable.

Informed Consent Statement: Not applicable.

Data Availability Statement: Not applicable.

Conflicts of Interest: The authors declare no conflict of interest. 


\section{Appendix A}

Our approach is rooted in our previous papers [43,45,47], but it presents also several differences. In particular, in the definition of the knowledge supply attributes (Section 3.1), we decided to consider only those that are inherent to the supply and relevant to the final aim of the present study, i.e., the measurement of the knowledge supply criticality and the openness degree of the open innovation practices used to manage it. Hence, with respect to the description provided in $[43,45]$, we decided not to include the knowledge collaboration approach, which we rather associate with the adopted innovation practice (as discussed below). Additionally, in the attempt to make the building blocks clearer, we decided to rename the knowledge attributes as knowledge kind and eliminate the reference to the knowledge categories. Finally, with respect to the description provided in [49], we decided not to include the knowledge transfer medium attribute, as it is not relevant for the measurement of the openness of innovation.

As for the innovation practices (Section 3.2), the dimensions are similar to those reported in [49], which, in turn, were a revision of the collaboration approach proposed in $[43,45]$, except for the dimension information flow, which we decided to eliminate because it is strictly dependent on the dimension interaction mode, and some dimensions that were simply renamed (degree of formality is now degree of formalization, coordination mode is now coordination mechanisms, output is now output accessibility, and coordination form is now relationship form). Finally, to make the openness of the adopted practices measurable, we added numerical values to each dimension.

As for the methodology reported in Section 4, in Step 1, instead of the simplified approach adopted to solve pairwise comparison matrices, we adopt an exact procedure, rooted in the Formula (1) and extensively described in the Appendix B. Step 3 is completely new.

\section{Appendix B. Explanation of Equation (1)}

The logarithmic least square method has been proposed in [55] as an alternative to the eigenvalue method [54] to solve pairwise comparison matrices. Let us assume that $A \in \mathbb{K}^{n \times n}$ is a pairwise comparison matrix having rank $n$, whose generic element $a_{i j}>0$ indicates the dominance of the item $i$ on the item $j$, as expressed by the Saaty's fundamental scale of judgement [44]. As demonstrated in [55], the weights vector associated with the matrix $A$ can be derived from the following optimization problem:

$$
\begin{gathered}
\min \sum_{i=1}^{n} \sum_{j>i}\left[\ln \left(a_{i j}\right)-\ln \left(\frac{w_{i}}{w_{j}}\right)\right]^{2} \\
\text { s.t. }\left\{\begin{array}{c}
\forall i=1, \ldots, n: w_{i}>0 \\
\sum_{i=1}^{n} w_{i}=1
\end{array}\right.
\end{gathered}
$$

whose solution is Equation (1). Specifically, the numerator at the second member of (1) is the geometric mean of the elements in the $i$-th row of the pairwise comparison matrix $A \in \mathbb{K}^{n \times n}$, whereas the denominator is the sum of the geometric means of all the rows of $A$ and acts as normalizing factor in order to satisfy the condition $\sum_{i=1}^{n} w_{i}=1$.

It should also be noted that the above methodology provides results that cannot be considered approximated compared to the eigenvalue method originally proposed in [54]. See [65] for further details.

\section{References}

1. Cirera, X.; Muzi, S. Measuring innovation using firm-level surveys: Evidence from developing countries. Res. Policy 2020, 49, 1-19. [CrossRef]

2. Guan, J.; Chen, K. Measuring the innovation production process: A cross-region empirical study of China's high-tech innova-tions. Technovation 2010, 30, 348-358. [CrossRef]

3. OECD (The Organisation for Economic Co-operation and Development). Oslo Manual: Guidelines for Collecting, Reporting, and Using Data on Innovation, 4th ed.; OECG Publishing: Paris, France, 2018. Available online: https://www.oecd.org/science/oslomanual-2018-9789264304604-en.htm (accessed on 23 December 2020). 
4. West, J.; Salter, A.; Vanhaverbeke, W.; Chesbrough, H. Open innovation: The next decade. Res. Policy 2014, 43, 805-811. [CrossRef]

5. Battistella, C.; De Toni, A.F.; Pessot, E. Practising open innovation: A framework of reference. Bus. Process. Manag. J. 2017, 23, 1311-1336. [CrossRef]

6. Bogers, M.; Zobel, A.K.; Afuah, A.; Almirall, E.; Brunswicker, S.; Dahlander, L.; Frederiksen, L.; Gawer, A.; Gruber, M.; Hae-fliger, S.; et al. The open innovation research landscape: Established perspectives and emerging themes across different levels of analysis. Ind. Innov. 2017, 24, 8-40. [CrossRef]

7. Drechsler, W.; Natter, M. Understanding a firm's openness decisions in innovation. J. Bus. Res. 2012, 65, 438-445. [CrossRef]

8. Knudsen, M.P.; Mortensen, T.B. Some immediate - but negative - effects of openness on product development performance. Technovation 2011, 31, 54-64. [CrossRef]

9. Marullo, C.; Martelli, I.; Di Minin, A. The many shades of 'openness': An application of item response theory to open innovation research. RED Manag. 2021, 51, 127-146. [CrossRef]

10. Hsieh, K.-N.; Tidd, J. Open versus closed new service development: The influences of project novelty. Technovation 2012, 32, 600-608. [CrossRef]

11. Chesbrough, H.; Brunswicker, S. Managing Open Innovation in Large Firms. In Survey Report: Executive Survey on Open Innovation 2013; FraunhoferVerlag: Stuttgart, Germany, 2013.

12. Felin, T.; Zenger, T.R. Closed or open innovation? Problem solving and the governance choice. Res. Policy 2014, 43, 914-925. [CrossRef]

13. Laursen, K.; Salter, A. Open for innovation: The role of openness in explaining innovation performance among UK manu-facturing firms. Strateg. Manag. J. 2006, 27, 131-150. [CrossRef]

14. Du, J.; Leten, B.; Vanhaverbeke, W. Managing open innovation projects with science-based and market-based partners. Res. Policy 2014, 43, 828-840. [CrossRef]

15. Bagherzadeh, M.; Markovic, S.; Bogers, M. Managing Open Innovation: A Project-Level Perspective. IEEE Trans. Eng. Manag. 2021, 68, 301-316. [CrossRef]

16. Dahlander, L.; O'Mahony, S.; Gann, D.M. One foot in, one foot out: How does individuals' external search breadth affect innovation outcomes? Strat. Manag. J. 2016, 37, 280-302. [CrossRef]

17. Gao, H.; Ding, X.-H.; Wu, S. Exploring the domain of open innovation: Bibliometric and content analyses. J. Clean. Prod. 2020, 275, 122580. [CrossRef]

18. Salter, A.; Criscuolo, P.; Ter Wal, A.L.J. Coping with Open Innovation: Responding to the Challenges of External Engagement in R\&D. Calif. Manag. Rev. 2014, 56, 77-94. [CrossRef]

19. Cano, J.A.; Londoño-Pineda, A. Scientific Literature Analysis on Sustainability with the Implication of Open Innovation. J. Open Innov. Technol. Mark. Complex. 2020, 6, 162. [CrossRef]

20. Chakrabarti, R.; Henneberg, S.C.; Ivens, B.S. Open sustainability: Conceptualization and considerations. Ind. Mark. Manag. 2020, 89, 528-534. [CrossRef]

21. Costa, J.; Matias, J.C. Open Innovation 4.0 as an Enhancer of Sustainable Innovation Ecosystems. Sustainability 2020, $12,8112$. [CrossRef]

22. Rasiah, R. Building Networks to Harness Innovation Synergies: Towards an Open Systems Approach to Sustainable Devel-opment. J. Open Innov. Technol. Mark. Complex. 2019, 5, 70.

23. Yun, J.J.; Liu, Z. Micro- and Macro-Dynamics of Open Innovation with a Quadruple-Helix Model. Sustainability 2019, 11, 3301. [CrossRef]

24. Chesbrough, H. To recover faster from Covid-19, open up: Managerial implications from an open innovation perspective. Ind. Mark. Manag. 2020, 88, 410-413. [CrossRef]

25. Temiz, S.; Broo, D.G. Open Innovation Initiatives to Tackle COVID-19 Crises: Imposter Open Innovation and Openness in Data. IEEE Eng. Manag. Rev. 2020, 48, 46-54. [CrossRef]

26. Lazzarotti, V.; Manzini, R. Different Modes of Open Innovation: A Theoretical Framework and an Empirical Study. Int. J. Innov. Manag. 2009, 13, 615-636. [CrossRef]

27. Trott, P.; Hartmann, D. Why 'Open Innovation' is old wine in new bottles. Int. J. Innov. Manag. 2009, 13, 715-736. [CrossRef]

28. Saebi, T.; Foss, N.J. Business models for open innovation: Matching heterogeneous open innovation strategies with business model dimensions. Eur. Manag. J. 2015, 33, 201-213. [CrossRef]

29. Chesbrough, H.W. Open Innovation: The New Imperative for Creating and Profiting from Technology; Harvard Business School Press: Boston, MA, USA, 2003.

30. Chesbrough, H. Open Business Models: How to Thrive in a New Innovation Landscape; Harvard Business School Press: Boston, MA, USA, 2006.

31. Chesbrough, H.; Bogers, M. Explicating open innovation: Clarifying an emerging paradigm for understanding innovation. In New Frontiers in Open Innovation; Chesbrough, H., Vanhaverbeke, W., West, J., Eds.; Oxford University Press: Oxford, UK, 2014; pp. 3-28.

32. Ahn, J.M.; Minshall, T.; Mortara, L. Open innovation: A new classification and its impact on firm performance in innovative SMEs. J. Innov. Manag. 2015, 3, 33-54. [CrossRef]

33. Cruz-González, J.; López-Sáez, P.; Navas-López, J.E.; Delgado-Verde, M. Open search strategies and firm performance: The different moderating role of technological environmental dynamism. Technovation 2015, 35, 32-45. [CrossRef] 
34. Huang, F.; Rice, J. Openness in Product and Process Innovation. Int. J. Innov. Manag. 2012, 16, 1250020. [CrossRef]

35. Spithoven, A.; Vanhaverbeke, W.; Roijakkers, N. Open innovation practices in SMEs and large enterprises. Small Bus. Econ. 2012, 41, 537-562. [CrossRef]

36. Michelino, F.; Lamberti, E.; Cammarano, A.; Caputo, M. Measuring Open Innovation in the Bio-Pharmaceutical Industry. Creativity Innov. Manag. 2014, 24, 4-28. [CrossRef]

37. Yun, J.J.; Avvari, M.V.; Jeong, E.S.; Lim, D.W. Introduction of an objective model to measure open innovation and its appli-cation to the information technology convergence sector. Int. J. Technol. Policy Manag. 2014, 14, 383-400. [CrossRef]

38. Burcharth, A.L.D.A.; Knudsen, M.P.; Søndergaard, H.A. Neither invented nor shared here: The impact and management of attitudes for the adoption of open innovation practices. Technovation 2014, 34, 149-161. [CrossRef]

39. Hung, K.P.; Chou, C. The impact of open innovation on firm performance: The moderating effects of internal R\&D and en-vironmental turbulence. Technovation 2013, 33, 368-380.

40. van de Vrande, V.; de Jong, J.P.J.; Vanhaverbeke, W.; de Rochemont, M. Open innovation in SMEs: Trends, motives and management challenges. Technovation 2009, 29, 423-437. [CrossRef]

41. Kobarg, S.; Stumpf-Wollersheim, J.; Welpe, I.M. More is not always better: Effects of collaboration breadth and depth on radical and incremental innovation performance at the project level. Res. Policy 2019, 48,1-10. [CrossRef]

42. Cassiman, B.; Di Guardo, M.C.; Valentini, G. Organizing links with science: Cooperate or contract? A project-level analysis. Res. Policy 2010, 39, 882-892. [CrossRef]

43. Bellantuono, N.; Pontrandolfo, P.; Scozzi, B. Mapping the Knowledge Supply Chain to foster Innovation. Int. J. Inf. Syst. Soc. Chang. 2013, 4, 1-17. [CrossRef]

44. Scozzi, B.; Bellantuono, N.; Pontrandolfo, P. Managing Open Innovation in Urban Labs. Group Decis. Negot. 2017, $26,857-874$. [CrossRef]

45. Scozzi, B.; Bellantuono, N.; Pontrandolfo, P. Assessing the openness degree of Knowledge Supply Chains. In Proceedings of the 21th International Conference on Production Research, Stuttgart, Germany, 31 July-4 August 2011.

46. Enkel, E.; Gassmann, O.; Chesbrough, H. Open R\&D and open innovation: Exploring the phenomenon. RED Manag. 2009, 39, 311-316. [CrossRef]

47. Bellantuono, N.; Pontrandolfo, P.; Scozzi, B. Different practices for open innovation: A context-based approach. J. Knowl. Manag. 2013, 17, 558-568. [CrossRef]

48. Dahlander, L.; Gann, D.M. How open is innovation? Res. Policy 2010, 39, 699-709. [CrossRef]

49. von Hippel, E. Comment on: Is open innovation a field of study or a communication barrier to theory development? Technovation 2010, 30, 555. [CrossRef]

50. Wikhamn, B.R. Two Different Perspectives on Open Innovation - Libre versus Control. Creativity Innov. Manag. 2013, 22, 375-389. [CrossRef]

51. Alexy, O.; Reitzig, M. Private-collective innovation, competition, and firms' counterintuitive appropriation strategies. Res. Policy 2003, 42, 895-913. [CrossRef]

52. Benkler, Y. Coase's Penguin, or, Linux and "The Nature of the Firm". Yale Law J. 2002, 112, 369. [CrossRef]

53. Benkler, Y.; Nissenbaum, H. Commons-based Peer Production and Virtue. J. Political Philos. 2006, 14, 394-419. [CrossRef]

54. Saaty, T.L. Decision making with the analytic hierarchy process. Int. J. Serv. Sci. 2008, 1, 83. [CrossRef]

55. Crawford, G.; Williams, C. A note on the analysis of subjective judgment matrices. J. Math. Psychol. 1985, 29, 387-405. [CrossRef]

56. Lynham, S.A. The general method of theory-building research in applied disciplines. Adv. Dev. Hum. Resour. 2002, 4, 221-241. [CrossRef]

57. Swanson, R.A.; Chermack, T.J. Theory Building in Applied Disciplines; Berrett-Koehler Publishers: Oakland, CA, USA, 2013.

58. Lazzarotti, V.; Manzini, R.; Pellegrini, L. Firm-specific factors and the openness degree: A survey of Italian firms. Eur. J. Innov. Manag. 2011, 14, 412-434. [CrossRef]

59. Pisano, G.P.; Verganti, R. Which kind of collaboration is right for you? Harv. Bus. Rev. 2008, 86, 78-86. [CrossRef]

60. Sobrero, M.; Roberts, E.B. Strategic management of supplier-manufacturer relations in new product development. Res. Policy 2002, 31, 159-182. [CrossRef]

61. Knapp, T.R. Treating ordinal scales as interval scales: An attempt to resolve the controversy. Nurs. Res. 1990, 39, 121-123. [CrossRef]

62. Preston, C.C.; Colman, A.M. Optimal number of response categories in rating scales: Reliability, validity, discriminating power, and respondent preferences. Acta Psychol. 2000, 104, 1-15. [CrossRef]

63. Churchill, G.A.; Peter, J.P. Research Design Effects on the Reliability of Rating Scales: A Meta-Analysis. J. Mark. Res. 1984, 21, 360. [CrossRef]

64. McDowell, I. Measuring Health: A Guide to Rating Scales and Questionnaires, 3rd ed.; Oxford University Press: New York, NY, USA, 2006; pp. 382-387.

65. Csató, L. A characterization of the Logarithmic Least Squares Method. Eur. J. Oper. Res. 2019, 276, 212-216. [CrossRef] 